\title{
Marina Caffiero, La Repubblica nella città del Papa
}

\section{Bernard Gainot}

\section{OpenEdition}

\section{Journals}

Édition électronique

URL : https://journals.openedition.org/ahrf/10780

DOI : 10.4000/ahrf.10780

ISSN : 1952-403X

Éditeur :

Armand Colin, Société des études robespierristes

Édition imprimée

Date de publication : 1 janvier 2009

Pagination : 231-232

ISBN : 978-2-200-92557-4

ISSN : 0003-4436

Référence électronique

Bernard Gainot, " Marina Caffiero, La Repubblica nella città del Papa », Annales historiques de la Révolution française [En ligne], 355 | janvier-mars 2009, mis en ligne le 01 décembre 2009, consulté le 24 avril 2022. URL : http://journals.openedition.org/ahrf/10780 ; DOI : https://doi.org/10.4000/ahrf. 10780

Ce document a été généré automatiquement le 24 avril 2022.

Tous droits réservés 


\title{
Marina Caffiero, La Repubblica nella città del Papa
}

\author{
Bernard Gainot
}

\section{RÉFÉRENCE}

Marina Caffiero, La Repubblica nella città del Papa, Roma 1798, Rome, Donzelli, 2005, 177 p., ISBN 88-7989-929-5, 23,90€.

1 Au moment où d'aucuns recyclent, pour évoquer la République directoriale, la vieille historiographie conservatrice de la fin du XIX siècle, tandis que d'autres jugent bon d'expédier l'expérience des républiques-sœurs en en faisant de simples appendices de l'armée française, l'ouvrage de Marina Caffiero, appuyé sur des recherches inédites, et prolongeant les études de Giuntella, de Maria Pia Donato, Davido Armando et Massimo Cattaneo, a quelque chose de tout à fait rafraîchissant.

2 Ce renouvellement fondamental des approches historiographiques des expériences républicaines dans la métropole pontificale, expériences exemplaires mais de courte durée, l'auteur nous le rappelle opportunément dans son introduction. Marina Caffiero nous présente ici quatre contributions organisées autour des transferts de sacralité, du régime pontifical à une nouvelle religion républicaine, qui est à la racine du radicalisme laïc du XIXe siècle. Elle insiste sur l'originalité de l'expérience, dans la mesure où les républicains romains cherchent (et trouvent en partie) leurs références dans la culture locale; nous sommes donc bien loin de l'imitation servile de la République française, tant de fois ressassée.

3 La première contribution explore les références antiques, à travers la filiation mythique avec la Rome républicaine, en rupture avec la critique historique érudite, qui connaît parallèlement un large développement au XVIII ${ }^{\mathrm{e}}$ siècle. Le retour à l'antique est un retour à un temps mythique des origines, une généalogie sur laquelle se fonde la nouvelle religion civile en gestation. L'auteur explore tout un milieu intellectuel local, artiste, érudit et antiquisant, qui a mis au goût du jour tout un système référentiel ; 
images, symboles et langages, tous clairement identifiables par un public large, auquel ces références s'adressaient à travers le langage des émotions. C'est le cas du bonnet phrygien, du culte de la déesse Liberté, de la construction d'un Panthéon civique autour des figures héroïques de Cola Di Rienzo, et des deux Brutus.

4 La deuxième contribution s'attache à la bataille des symboles, qui fait rage dans les Conseils de la nouvelle république ; un pôle négatif, c'est la destruction des symboles de l'Ancien Régime, et un pôle positif, c'est l'affirmation d'un radicalisme laïc à travers précisément le recours à l'antique. Marina Caffiero met en lumière les protagonistes du débat législatif qui prélude à la cérémonie du 17 juillet 1798, pour la mise en scène de la destruction du Livre d'Or, le registre de l'aristocratie romaine, et des registres du SaintOffice. Au cours de ce débat, dans lequel s'affrontent radicaux et modérés, se joue l'invention d'un système de symboles destinés à la fabrication du consensus populaire. Les artistes sont intégrés à une politique républicaine spécifiquement romaine, avec en arrière-plan un autre débat, non moins important, autour de la propriété collective ou individuelle des œuvres d'art. Tandis que les radicaux s'attachent à l'éradication des emblèmes « du féodalisme et de la superstition" pour introduire une rupture totale avec la Rome pontificale, les modérés cherchent à épargner les monuments culturels comme buttes témoins des beaux-arts, de l'érudition et de l'histoire. Le radical Gagliuffisouligne que les noms influent sur les choses, et que nommer de façon neuve des choses nouvelles doit imprimer ces dernières dans les consciences individuelles et aider à créer l'intégration sociale, l'identité collective. L'acuité du langage révolutionnaire est un puissant instrument du changement social.

5 La symbolique des institutions républicaines (le calendrier décadaire, les fêtes civiques) est ainsi placée dans un autre contexte que le contexte français, tandis que sont revisitées des notions comme la « régénération » ou le nominalisme des Idéologues.

6 Reste à mesurer à quel point la revendication égalitaire, le rôle des symboles et des images, la sacralisation du pouvoir et de la vertu fondatrice de la nouvelle idée de patrie étaient tributaires en fait de la formation religieuse et bien souvent ecclésiastique de l'élite dirigeante romaine, et c'est l'objet de la troisième contribution, qui porte sur ce transfert de sacralité.

7 L'auteur emprunte très largement, mais avec une distance critique, à la thèse de George Mossé sur la " nationalisation des masses ", et tout particulièrement l'« esthétisation de la politique ». À travers cette dernière s'opèrent la nationalisation et la politisation des masses, et se crée une liturgie politique. Le processus se construit dans un affrontement et une concurrence avec la religion chrétienne traditionnelle, à laquelle la nouvelle religion civique emprunte rites et symboles.

8 Ce transfert est patent lors de la cérémonie funèbre organisée en l'honneur du général Duphot, assassiné lors d'une manifestation antifrançaise. Le discours funèbre est prononcé par un ex-ecclésiastique sur la place Saint-Pierre de Rome, ce même « citoyen Gagliuffi», pour qui «les noms ont de l'influence sur les choses»; il est truffé de références à la pureté primitive du christianisme.

9 La religion traditionnelle réagit en retour en interprétant ces manifestations républicaines comme une résurgence de l'hérésie. On reste donc dans le même univers culturel, avec inversion des référents (les arbres de la liberté remplacent les croix, et inversement, par exemple). La nouvelle culture républicaine est perçue comme antagonique de la religion romaine établie, mais symétrique et parallèle. L'accusation de «superstition» est retournée contre les républicains avec une large utilisation de 
l'ouvrage de La Harpe, Du fanatisme dans la langue révolutionnaire, quasi simultanément traduit en italien en 1797. Il y a bataille sémantique dans le même champ rhétorique.

La dernière contribution revient sur le cas de la « prophétesse » Suzette Labrousse, déjà étudiée par Renzo de Felice, mais placée ici dans une autre perspective, celle des rapports entre le mesmérisme, le millénarisme et la revendication féministe. Suzette Labrousse a largement recours au magnétisme animal. Toute maladie, corporelle ou sociale, a des causes tantôt physiques, tantôt morales, ce qui est reconnaître les liens entre médecine et politique. Des corps régénérés (sauvés de la corruption) améliorent la morale, et une morale plus saine produit finalement ses effets aussi bien sur le plan politique que sur le plan religieux.

11 Suzette Labrousse, qui a accueilli avec enthousiasme la Révolution arrive à Rome en 1798 pour prêcher le nouvel évangile démocratique, dans lequel les femmes, tout comme les minorités (les juifs) doivent avoir toute leur place. Marina Caffiero analyse les discours prononcés au Cercle constitutionnel par la prophétesse. Là où plusieurs historiens n'ont vu qu'un délire mystique, l'auteur restitue une cohérence ; l'imposition des mains est une pratique thérapeutique pour trouver un équilibre psycho-physique. Cette pratique suppose des qualités positives: un bon caractère, une bonne âme, un cœur compatissant aux souffrances des humbles. L'insistance est mise sur la naissance, le moment de l'accouchement, ce qui est une voie pour assurer une place essentielle aux femmes, emblématisant leur rôle de médiatrices.

12 Ce ne sont pas quatre contributions juxtaposées, mais un glissement d'une thématique à l'autre, chaque étude prolongeant la précédente, et illustrant heureusement l'interrogation centrale de la construction d'une religion civique.

13 Ces études complètent parfaitement le volume récent consacré à la politique symbolique, sous la direction de Nathalie Scholz et Christina Schroër, et témoignent de la vitalité de la recherche dans un domaine encore trop peu exploré. 